\title{
A modernidade é de fato universal? Reemergência, desocidentalização e opção decolonial
}

\author{
Is modernity really universal? \\ Reemergence, dewesternization and decolonial option \\ Júlio Roberto de Souza Pinto*
Walter D. Mignolo**
}

Resumo: Neste ensaio, argumentamos: (1) que modernidade não é o desenrolar ontológico de uma história universal, mas sim a interpretação de certos eventos por atores e instituições que se viam e se veem como estando no centro da terra e no presente de um tempo universal; (2) que essa interpretação é local e regionalmente condicionada, é europeia ocidental, embora se apresente como universal e global; ou seja, a enunciação é local em que pese o enunciado ser global; (3) que, por trás de um discurso triunfalista, a modernidade esconde os horrores que a constituem: a colonialidade; essa é a razão mesma por que entendemos que modernidade não pode ser compreendida sem colonialidade e que a colonialidade não pode ser superada pela modernidade; e (4) que a essa retórica de salvação da humanidade e suas expressões mais recentes desenvolvimento e globalismo -, articulada por agentes e instituições que controlam a produção do conhecimento e traduzem os próprios privilégios em promessas para o resto do mundo, assim como o projeto de dominação cultural, econômica e política que ela promove, especialmente a partir da segunda década do século 20 vêm apresentando sinais de enfraquecimento, na mesma proporção em que discursos e projetos dissidentes de re-existência, entre os quais a opção decolonial, baseada na qual formulamos nosso argumento, vêm ganhando força.

Palavras-chave: Modernidade. Universalismo. Ocidentalização. Colonialidade. Desocidentalização. Decolonialidade.

\footnotetext{
*Doutor em Sociologia pela Universidade de Brasília (UnB, Brasília, DF, Brasil), professor do mestrado profissional em Poder Legislativo da Câmara de Deputados (Brasília, DF, Brasil) e pesquisador visitante do Centro de Estudos Globais e Ciências Humanas da Universidade de Duke (EUA)<julio.pinto@camara.leg.br>.

**Doutor em Semiótica e Teoria Literária pela École des Hautes Études (EPHE, Paris, França), catedrático William H. Wannamaker, diretor do Center for Global Studies and the Humanities, professor da Universidade de Duke (EUA)<wmignolo@acpub.duke.edu>.
} 


\begin{abstract}
In this essay, we argue: (1) that modernity is not the ontological unfolding of a universal history, but rather the interpretation of certain events by actors and institutions that saw and see themselves as being in the center of the Earth and in the present of a universal time; (2) that this interpretation is locally and regionally conditioned, it is Western European, despite presenting itself as universal and global; that is, the enunciation is local in spite of the enunciated be global; (3) that, behind a triumphalist discourse, modernity hides the horrors that constitute it: coloniality; this is the very reason why we believe that modernity can not be understood without coloniality and coloniality can not be overcome by modernity; and (4) that this rhetoric of salvation of mankind and its most recent expressions - development and globalism -, articulated by agents and institutions that control the production of knowledge and translate their own privileges into promises for the rest of the world, as well as the project of cultural, economic and political domination that it promotes, especially starting from the second decade of the twentieth century have shown signs of weakening, in the same proportion as dissident discourses and projects of re-existence, including the de-colonial option based on which we formulate our argument, have gained strength.
\end{abstract}

Keywords: Modernity. Universalism. Westernization. Coloniality. Dewesternization. Decoloniality.

\title{
Introdução
}

Quando a ideia de Brasil foi inventada e como essa invenção se tornou o fundamento de uma história territorial que apagou outras memórias e territorialidades? O Brasil é parte da modernidade inventada no processo de constituir a si mesma como modernidade. À época não era modernidade a palavra usada, mas re-nascimento. A invenção do Brasil foi precedida pela invenção das "Índias Ocidentais" e do "Novo Mundo", este último termo utilizado pelos europeus para designar tudo aquilo que eles não conheciam. A invenção dessa história territorial justificou a supressão e até mesmo o genocídio de outras territorialidades e memórias em nome do renascimento e da salvação. O discurso emergente, o discurso que se tornou o fundamento histórico do que mais recentemente tem sido narrado e celebrado como "modernidade", homogeneizou as grandes civilizações de Anahuac e Abya Yala em barbáricos "índios". E a invenção do Brasil, juntamente com a invenção do Novo Mundo, contribuiu para a justificação de um segundo genocídio sobre o qual o imaginário de modernidade foi construído: o genocídio dos africanos escravizados.

Neste ensaio, argumentamos (1) que modernidade não é o desenrolar ontológico de uma história universal, mas sim a interpretação de certos eventos por atores e instituições que se viam e se veem como estando no centro da Terra e no presente de um tempo universal; (2) que essa interpretação é local e regionalmente condicionada, é europeia ocidental, embora se apresente como 
universal e global; ou seja, a enunciação é local em que pese o enunciado ser global; (3) que, por trás de um discurso triunfalista, a modernidade esconde os horrores que a constituem: a colonialidade; essa é a razão mesma por que entendemos que modernidade não pode ser compreendida sem colonialidade e que a colonialidade não pode ser superada pela modernidade; e (4) que a essa retórica de salvação da humanidade e suas expressões mais recentes desenvolvimento e globalismo -, articulada por agentes e instituições que controlam a produção do conhecimento e traduzem os próprios privilégios em promessas para o resto do mundo, assim como o projeto de dominação cultural, econômica e política que ela promove, especialmente a partir da segunda década do século 20 vêm apresentando sinais de enfraquecimento, na mesma proporção em que discursos e projetos dissidentes de re-existência, entre os quais a opção decolonial, baseada na qual formulamos nosso argumento, vêm ganhando força.

Discurso, no sentido em que o empregamos neste ensaio, transcende a simples ideia de pronunciamento oral ou escrito para referir-se a todo um conjunto de percepções de si e do mundo que as diferentes comunidades de sujeitos elaboram interativamente. Inclui cosmologia, arte, filosofia, ciência, tecnologia, forma de organização econômica e política, direito. Em muitos contextos, é sinônimo de imaginário, narrativa e mesmo retórica, na acepção de discurso orientado à persuasão de ouvintes e leitores.

Do mesmo modo, colonialidade ou colonialidade do poder transcende a mera noção de colonialismo para referir-se ao conjunto de princípios baseados nos quais a narrativa salvacionista e triunfalista de renascimento e modernidade foi construída justificando expropriação, exploração e toda sorte de violência em nome de uma salvação cristã ou de um renascimento e progresso seculares. Colonialidade do poder refere-se, pois, a um código conceitual fundamentado no qual a ideia de civilização ocidental legitima a si mesma - por meio de atores, instituições, linguagens - como controladora não só da economia e da autoridade, mas também da subjetividade e do conhecimento de povos e etnias não ocidentais. A desumanização de habitantes não europeus do globo foi necessária para justificar o controle de tais "seres humanos inferiores". Racismo como o conhecemos hoje foi estabelecido àquela época. Racismo não é biológico, mas sim epistêmico; é a classificação e a hierarquização de umas pessoas por outras que controlam a produção do conhecimento, que estão em posição de atribuir credibilidade a tal classificação e hierarquização e que estabelecem a si mesmas como o padrão: "os humanos" - todos os demais são apenas diferentes graus de quase ou semi-humanos. Colonialidade é, portanto, constitutiva de modernidade. Modernidade-colonialidade - expressão 
pela qual descrevemos esse fenômeno - é, por conseguinte, sinônimo de ocidentalização. Ocidentalização designa o conjunto de projetos globais sempre em mutação e adaptação - que visam à disseminação dos valores da civilização ocidental em escala planetária.

Decolonialidade, por sua vez, abrange não apenas os movimentos de transformação das ex-colônias europeias em estados-nações independentes - descolonização -, como também os esforços de desligamento ou desengajamento subjetivo, epistêmico, econômico e político em face do projeto de dominação ocidental, esforços que antecederam tais movimentos de descolonização, ainda que só tenham vindo a ganhar musculatura a partir da Conferência de Bandung em meados da década de 1950. A Bandung, na verdade, estão relacionados três projetos de contestação dos valores universais da civilização ocidental e de sua pretensão de dominar o mundo. O primeiro deles, a descolonização, já estava andamento na África e na Ásia. Nesse sentido, Bandung se transformou na organização de países não alinhados. Noutra ponta, um novo projeto surgia: desocidentalização. Desocidentalização consiste não na rejeição do capitalismo, mas em sua apropriação. A primeira tentativa bem sucedida nessa direção foi Cingapura; a segunda foi a China desde Deng Xiaoping. O terceiro projeto a guardar relação com Bandung, decolonialidade ou opção decolonial ganhou especial robustez a partir do início dos anos 1990 depois que o insucesso da descolonização da África e da Ásia ficou evidente e o fracasso do socialismo restou patente no colapso da União Soviética. Decolonialidade adquiriu a forma que aqui esboçamos nos Andes sul-americanos, em decorrência dos limites apresentados pela teoria da dependência e a partir da obra do peruano José Carlos Mariátegui. Aníbal Quijano, também peruano, chamou a atenção para o fato de que modernidade e colonialidade são dois lados da mesma moeda e para a consequente e urgente necessidade de um desligamento ou desengajamento das ficções da modernidade e das violências da colonialidade (Quijano, 1998, 2005, 2007). Um dos alvos da decolonialidade, portanto, é a recorrente análise do fenômeno da modernidadecolonialidade, que é justamente o que nos propomos a fazer neste ensaio.

Mas isso não é tudo. A decadência da ocidentalização sob a presidência de George W. Bush nos Estados Unidos e a emergência da desocidentalização levaram à necessidade de renovação da ocidentalização numa nova base. Essa foi a primeira movimentação do presidente norte-americano Barack Obama no cenário internacional. E tal projeto está em plena execução hoje na Ucrânia, no Oriente Médio, nas tentativas de limitar as movimentações da China no Pacífico, no restabelecimento das relações com Cuba associado com o controle da América Central e a desestabilização do Brasil, da Argentina e da Venezuela. 
Chamemos de reocidentalização o renascimento de mais de quinhentos anos de ocidentalização.

\section{Modernidade como discurso}

A elucidação da natureza discursiva da modernidade e seus correlatos - civilidade, desenvolvimento, democracia - nos parece ser preliminar até mesmo ao desvelamento do seu caráter local, provincial, mais ainda a seu descortinamento como projeto de dominação epistêmica, econômica e política do mundo.

Com efeito, toda relação do ser humano com o meio físico é mediada pela linguagem, e linguagem necessariamente envolve interação social e simbólica. Não há, pois, verdade objetiva ou direta representação do mundo exterior. Tudo que existe é verdade intersubjetiva ou verdade construída na e pela interação dos sujeitos, por meio do processo de verificação ou produção coletiva da verdade. Verdade científica, nesse sentido, é aquela verdade produzida pela comunidade científica, ou seja, aquela verdade construída nos termos e na forma admitidos pela comunidade dos cientistas e, por isso mesmo, por eles ratificada ou homologada, e não simplesmente pela dialética estabelecida entre hipótese e experimentação. Nada é mais ingênuo do que a suposição de que a mera tabulação de dados, tidos e havidos como amostras de uma realidade pretensamente exterior às interações sociais e simbólicas, como que automaticamente resulte numa representação direta e imediata dessa realidade.

Modernidade, desenvolvimento, democracia e direitos humanos, portanto, não existem como realidades objetivas, tampouco são suas conceituações representações diretas ou imediatas de tais supostas realidades exteriores. Modernidade, desenvolvimento, democracia e cidadania, assim como mercado, estado e nação são realidades discursivas, constituídas e validadas no curso das interações simbólicas nem sempre plenamente conscientes entre sujeitos individuais e coletivos, tanto no plano micro quanto no plano macro, espacial e temporalmente.

À modernidade, no entanto, interessa ocultar esse seu caráter discursivo, político. A ela interessa apresentar-se como realidade objetiva, "natural", necessária e inevitável, eliminando, assim, toda e qualquer possibilidade de contestação e de reexistência ou busca de outros mundos. Daí por que entendemos que a dominação econômica e política, que também se esconde por trás da retórica ocidental de modernidade, emancipação (liberal ou marxista), desenvolvimento e democracia, começa e termina com a dominação cultural, da informação e do conhecimento. Enquanto a dominação política chegou ao fim 
com a transformação das colônias e de fragmentos das antigas civilizações em estados-nações independentes, e o domínio econômico, depois de globalizado, começa a apresentar sinais de exaustão, a dominação cultural, da informação e do conhecimento segue dando mostras de vitalidade e vigor nas universidades, nos museus, teatros e cinemas, nos jornais, nas redes de televisão e demais meios de comunicação pelo mundo afora. Na verdade, a cultura, a informação e o conhecimento sempre foram esferas privilegiadas de dominação econômica e política. A diferença é que nestes dias de capitalismo tardio ou pós-fordista esse fato ficou mais evidente.

Mas, se por um lado, é no ser discurso sem se declarar como tal, apresentando-se antes como realidade objetiva, "natural", inexorável, que o projeto de dominação ocidental encontra sua força, por outro, é também aí que reside sua fraqueza. Em outras palavras, é exatamente devido à sua natureza discursiva que a modernidade e o projeto de dominação ocidental que por trás dela se esconde como uma espécie de subtexto podem ser contestados e novas formas de coexistência humana podem ser imaginadas e articuladas. Não é por outra razão que o primeiro e mais fundamental passo proposto pela opção decolonial é justamente o desligamento ou desengajamento epistêmico.

\section{Modernidade como discurso local com pretensões universais}

A modernidade e seus correlatos - civilidade, desenvolvimento, democracia e direitos humanos - não somente são realidades discursivas; são também narrativas articuladas a partir das experiências históricas e locais de diferentes povos europeus, ainda que se apresentem como verdades objetivas, "naturais", universais, comuns a todos os povos que habitam o planeta.

Ao longo dos tempos, os diferentes agrupamentos humanos têm articulado discursos a partir das próprias histórias locais, formas de interação e comunicação, crenças, ciências e instituições. À medida que os agrupamentos humanos têm interagido uns com os outros, os discursos têm aumentado seu alcance, transcendendo limites espaciais e temporais, o que, por sua vez, tem ampliado o âmbito das interações. Nunca, entretanto, qualquer outro discurso chegou a atingir caráter tão universalista e totalitário como o articulado pelos europeus ocidentais a partir do século 16 .

A começar com o Renascimento e culminando com o Iluminismo, os europeus passaram a se ver como sendo o centro do mundo e o clímax da evolução humana. Não apenas criaram uma geografia em que se localizam no centro e os outros povos são localizados na periferia, mas também inventaram uma história em que se situam no presente de uma linha do tempo que evolui de um estado da natureza a um estado racional, civilizado, e os 
demais povos, embora contemporâneos, são situados no passado, são primitivizados.

Nesse discurso, italianos, espanhóis e portugueses, a partir do Renascimento, e holandeses, britânicos, franceses e alemães, desde o Iluminismo, representam sua visão de mundo como sendo a visão de todo mundo; sua cultura, literatura, arte, filosofia, ciência, forma de organização econômica e política como sendo universais. Apresentam a si próprios como a forma final e acabada da humanidade.

Tal discurso de modernidade, racionalidade, desenvolvimento, democracia e direitos humanos não somente procura esconder seu caráter local, regional, europeu, por trás de uma máscara universal, mas também busca ocultar a participação de não europeus em sua articulação dialógica. $\mathrm{Na}$ verdade, os não europeus, "não ocidentais" são totalmente excluídos do diálogo, sequer são considerados Outros propriamente ditos; ao contrário, são dessubjetivizados, reduzidos a meros objetos de estudo, dominação e exploração. Mais: não apenas nega a participação de não europeus em sua articulação dialógica, por não considerá-los sujeitos - não admitindo, por exemplo, o fato de que não haveria Europa se não existissem a América, a África e a Ásia -, o discurso europeu ocidental suprime todo e qualquer outro discurso. Ou seja, além de se apresentar como totalidade, o discurso europeu ocidental é também totalitário.

Daí por que o desligamento ou desengajamento epistêmico - o primeiro e mais importante passo na direção da decolonialidade, ao qual já nos referimos na parte anterior - implica a adoção de uma geopolítica e uma corpopolítica do conhecimento que, de um lado, denuncie a pretensão universal e portanto o totalitarismo de uma particular etnia (corpopolítica) localizada numa parte específica do planeta (geopolítica) e, de outro, crie condições de possibilidade para a contestação e a reexistência de outras etnicidades numa espécie de pluriversalidade.

\section{Modernidade como colonialidade}

Discursividade e localidade, no entanto, não são tudo o que se esconde no subtexto do discurso de modernidade. Por trás da retórica de emancipação, desenvolvimento, tecnologia, democracia e direitos humanos também se oculta um projeto de dominação epistêmica, econômica e política do mundo, inicialmente liderado pela Espanha e Portugal (do século 16 a meados do século 18), depois pela Holanda, Grã-Bretanha e França (de meados do século 18 a meados do século 20), e finalmente pelos Estados Unidos (de meados do século 20 aos dias de hoje). 
Obviamente, o período que antecede o século 16 registra outros casos de expansão colonial e imperial, mas nenhum apresentou a mesma natureza e o mesmo alcance do colonialismo e do imperialismo modernos. Diferentes formações sociais se desenvolveram em diversas regiões do mundo num movimento expansionista que envolveu a colonização de várias outras localizadas em suas margens e certo controle sobre tantas outras situadas em suas submargens. Nenhuma, contudo, chegou ao ponto de articular um discurso tão universalista e totalitário como o que veio a ser estruturado pelos europeus ocidentais a partir do Renascimento. Podemos até considerar algumas dessas formações sociais antigas como impérios, mas jamais qualquer delas chegou a se tornar tão imperialista quanto a moderna Europa ocidental e seu legatário anglo-americano, os Estados Unidos.

Assim é que, a partir do "marco zero" e do "topo da escalada civilizatória", e tomando a própria cosmologia, ciência e tecnologia, forma de organização econômica e política como valores e regras universais, os europeus saíram a dividir o mundo entre ocidente e oriente, norte e sul, bárbaros e civilizados, tradicionais e modernos, criando novas identidades sociais, como "índio", "negro" e "mestiço", e recriando outras tantas. "Espanhóis", "portugueses" e, mais tarde, "europeus", que antes simplesmente indicavam origem geográfica, adquiriram, em relação a essas novas identidades, conotação racial (Quijano, 2005).

Com a bênção papal, os reis católicos da Espanha e Portugal dividiram entre si as imensas porções de terra por seus navegantes e mercadores "descobertas" em suas tentativas de chegar às Índias pelo oeste (Tratado de Tordesilhas, 1494), razão pela qual as denominaram "Índias Ocidentais". Anos depois, em 1529 foi a vez de as "Índias Orientais" serem repartidas entre esses dois impérios cristãos (Tratado de Saragoça). Um pouco mais de um século à frente, as novas potências europeias, Holanda, Grã-Bretanha e França, passaram a disputar com espanhóis e portugueses o controle e a exploração dos territórios e dos povos da América, da Ásia e da África. Para aquém das linhas divisórias globais, reinava o estado de direito; em outras palavras, as várias formações sociais europeias, já estruturadas como estadosnações (na verdade, uma combinação indissociável de capital, estado e nação), regulavam-se pelo direito interestatal ou internacional. Para além de tais linhas divisórias, imperava o estado da natureza e o mundo era "livre" - livre para ser dominado, apropriado e explorado. De fato, a partir do momento que os europeus ocidentais se inventaram como estados-nações, em suas interações e intercâmbios com outros povos e etnias, a nada e a ninguém reconheciam como sujeito a menos que tivesse a mesma configuração. Em outras palavras, 
todas as demais formações sociais que igualmente não se estruturassem como estados-nações eram mantidas na exterioridade por eles criadas no processo de invenção de si mesmos como interioridade.

É oportuno destacarmos, nesta altura do argumento, nosso entendimento de que essa exterioridade criada pelos europeus é antes de tudo subjetiva e epistêmica. Não somente as terras localizadas no lado de fora do estado de direito ou da cosmópolis europeia estavam livres à ocupação e à exploração, mas também os diferentes povos situados nesse estado da natureza, depois de dessubjetivizados, podiam ser reduzidos a objetos de dominação e expropriação. Sob uma retórica primeiramente salvacionista, depois civilizatória e finalmente desenvolvimentista, povos e etnias posicionadas na periferia do novo centro do mundo, inclusive antigos impérios, em diferentes graus, têm sido desapropriados de suas terras; têm visto suas cosmologias, manifestações artísticas, ciências e tecnologias, formas de organização econômica e política serem reduzidas a superstições, mitos, folclores, tradições irracionais e idiossincrasias, quando não são totalmente suprimidas. Sob uma retórica emancipatória, povos e etnias periferizadas têm sido destituídas de sua subjetividade e dignidade.

A América e os povos originários desse continente foram os primeiros a sentir mais fortemente o impacto do esforço salvacionista, civilizatório e desenvolvimentista dos europeus ocidentais. Ao argumento de que resistiam às tentativas de salvá-los do paganismo e do primitivismo a que supostamente se encontravam aprisionados, os vários povos e etnias que milenarmente habitavam o continente americano, do sul ao norte, foram desapropriadas de suas terras, removidas e circunscritas a áreas "reservadas", pobres de recursos e impróprias a suas formas de organização econômica e política. Submetidos a um esmagador processo de dominação cultural, suas vozes foram silenciadas, suas memórias - inclusive de resistência - foram apagadas, suas crianças lhes foram arrancadas e internadas em escolas-fábricas de ocidentalizados. Sem passado nem futuro, os que não foram confinados, foram submetidos a trabalho forçado, e os que sobreviveram ao extermínio - e muitos milhões foram exterminados já nos primeiros contatos com os europeus ocidentais - foram reduzidos à condição de "índios".

E a situação desses povos originários da América e do relativamente pequeno contingente de indivíduos que deles restou não melhorou com a reprodução dos estados-nações europeus em solo americano. Ao contrário, a presença desses povos originários tem sido quase que inteiramente obliterada ou invisibilizada ou, quando menos, obscurecida no norte da América e no Cone Sul. Nas demais regiões do continente americano, do Brasil ao México, uma maioria de "índios" e "mestiços" tem sido duplamente colonizada, 
mantida na "periferia da periferia" ou na "exterioridade da exterioridade" por uma elite branca ou branqueada, por sua vez conservada em dependência cultural e econômica em relação às potências centrais do Atlântico Norte, desde meados do século 20 sob a liderança suprema dos Estados Unidos.

Os impactos do esforço salvacionista, civilizatório e desenvolvimentista europeu ocidental, e do projeto de dominação cultural, econômica e política que por trás dele se esconde, não foram menos violentos na África e em seus habitantes. À semelhança dos povos originários da América, os diferentes povos e etnias africanas, especialmente as subsaarianas, foram submetidas a um brutal controle e gerenciamento subjetivo e epistêmico, além de econômico e político. Diferentemente de seus consortes americanos, no entanto, por terem sido posicionados, por força de argumentos inicialmente cristão-teológicos e posteriormente científico-biológicos, no mais primitivo estágio da linha de evolução humana articulada no discurso eurocêntrico de modernidade, os subsaarianos, em sua grande parte, foram reduzidos a mera mercadoria, tendo sido comercializados sobretudo na América, para onde foram massivamente exportados e utilizados como mão de obra escrava, até quando, por razões mais econômicas do que éticas, ou melhor, por força de uma ética econômica, foram trocados por trabalhadores assalariados, muitos dos quais imigrados de regiões periféricas da Europa.

A propósito disso, convém salientarmos nesta altura de nosso argumento que a ideia segundo a qual a relação capital-trabalho teria evoluído de um regime de escravidão, passando por um regime de servidão até chegar um regime de trabalho assalariado nada mais é do que uma criação eurocêntrica, seja ela em sua versão liberal ou marxista. Na verdade, assim como fizeram com as noções de mercado, estado e nação, os europeus ocidentais articularam, em suas interações e intercâmbios com outros povos e etnias, os regimes de escravidão, servidão e trabalho assalariado, e os distribuíram entre as identidades sociais por eles inventadas: aos "negros", a escravidão; aos "índios", a servidão; e aos "brancos", o trabalho assalariado. Com a expansão da dominação europeia ocidental, essa divisão racial do trabalho foi imposta em escala global, com a consequente criação de novas identidades sociais, como os "amarelos" por exemplo (Quijano, 2005). Assim é que o trabalho escravo é tão moderno quanto o trabalho assalariado, sendo até hoje a grande parte da população das regiões periféricas, em sua maioria pessoas de cor, mantida sob aquele regime de trabalho forçado ou a ele análogo, para sustentar as respectivas elites brancas ou branqueadas, ocidentalizadas, e uma minoria branca, "civilizada", "desenvolvida" e "democrática" confortavelmente ins- 
talada no novo centro do mundo, o Atlântico Norte, a despeito de toda uma retórica emancipatória, seja ela liberal ou marxista.

Mas voltemos à discussão da condição de vida dos africanos da diáspora, particularmente da diáspora americana, do enorme contingente de indivíduos que, dessubjetivados e reduzidos a meros objetos, foram brutalmente desarraigados de diferentes regiões, povos e etnias da África para, transformados em commodities e homogeneizados como "negros", aqui serem utilizados como mão de obra escrava. Mesmo depois da extinção do regime escravista - em alguns lugares, como no Brasil, bem mais tardiamente do que em outros -, os "negros" não têm tido melhor sorte do que os "índios". Ao contrário, como já argumentamos, por haverem sido posicionados no estágio mais primitivo da linha de evolução humana inventada pelos europeus ocidentais, os "negros" têm sofrido maior violência física e simbólica. Se os "índios”, em que pese a terem sido desapropriados, removidos e confinados, ainda têm uma terra a reivindicar e uma memória nela fulcrada, os "negros", diferentemente, tiveram suas raízes arrancadas da África e aqui nunca foram propriamente enxertados. Vivem como que num não espaço, num não lugar, e assim são mantidos como um exército de trabalho de reserva. Quando ousam ocupar algum espaço, são implacavelmente criminalizados e até mesmo sumariamente executados. Nos Estados Unidos, embora sejam apenas 13,2\% da população total do país (US Census Bureau, 2015), ${ }^{1}$ constituem desproporcionais $37,6 \%$ da população carcerária (Federal Bureau of Prison, 2015). E o que é mais assustador: representam 50\% das vítimas de homicídio naquele país (FBI, 2011). ${ }^{2}$ No Brasil, a situação não é diferente, apesar de escamoteada por trás do discurso da democracia racial articulado pela elite branca ou branqueada e internalizado por grande parte da população. Embora constituam a maioria da população brasileira (pelo menos 50,94\%; IBGE, 2010), ${ }^{3}$ negros e mestiços são os grandes ausentes nas principais universidades e centros de pesquisas, ${ }^{4}$ nas sedes das grandes empresas e corporações, nas bolsas de valores, nos palácios governamentais, nas casas legislativas e nos tribunais de justiça, enfim nos principais espaços de exercício de poder epistêmico, econômico e político. Em contrapartida, sua presença nas carceragens do país é ostensiva (54\%; Depen, 2012), excedendo

\footnotetext{
${ }^{1}$ Dados de 2013.

2 Não estão aí incluídos os chamados "homicídios justificados".

${ }^{3}$ Pela primeira vez na história mais brasileiros se declararam negros e pardos (mestiços de negros) do que brancos $(50,94 \%$, contra $47,51 \%$; os restantes $1,55 \%$ distribuem-se entre amarelos e indígenas) (IBGE, 2010).

${ }^{4}$ A não ser mais recentemente, e de maneira ainda muito tímida e inexpressiva, por força da política de cotas adotadas pelo governo federal (Lei n. 12.711/12).
} 
sua parcela na população do país. Mais ostensiva ainda - e alarmante - é sua presença entre as vítimas de homicídio (71,1\%; Waisefisz, 2012). ${ }^{5}$

Mas nem os diversos povos e etnias localizadas nas regiões centrais e marginais das antigas civilizações asiáticas conseguiram resistir à sedução da retórica ocidental de modernidade, civilidade, desenvolvimento e democracia, havendo igualmente sucumbido ao projeto de dominação que por trás dela se esconde. O controle e o gerenciamento ocidental sobre os povos e etnias do Oriente Médio e do Extremo Oriente, contudo, não foram tão devastadores como foram e têm sido sobre os povos e etnias da América e da África, o que se explica pelo posicionamento dos orientais ou asiáticos em estágio mais avançado do que aquele em que foram posicionados negros e ameríndios na linha de evolução humana inventada pelos europeus, como também pela presença naquela região de antigas civilizações e potências militares. Ninguém, no entanto, escapou ao processo de desumanização e humilhação imposto pelos ocidentais ao resto do mundo.

Tomemos o caso da China por exemplo. Antes mesmo da era cristã, os chineses iniciaram a articulação de um discurso com base no qual mantiveram uma poderosa organização cultural, econômica, política e militar até o século 20. Tanto no campo científico e tecnológico quanto na esfera governamental, os chineses estavam bem à frente dos europeus quando Marco Polo os "visitou" no século 13. De modo que, quando os primeiros mercadores, missionários e soldados ocidentais chegaram à China, encontraram uma rica e antiga civilização. Deixaram no seu rastro, entretanto, ruína e humilhação. As chamadas guerras do ópio são emblemáticas. A primeira delas, de 1839 a 1842, foi precipitada pelos esforços do governo da China de impedir que comerciantes britânicos continuassem a vender ópio à população daquele país. A droga estava destruindo a saúde e a vida de um número alarmante de chineses, porém era grande fonte de lucro para negociantes ocidentais, especialmente britânicos, mas também americanos e franceses, a tal ponto de se constituir importante fator de equilíbrio na balança comercial entre a Grã-Bretanha, os Estados Unidos e a França, de um lado, e a China, de outro. De sorte que, quando em 1839 a China tentou banir a importação de ópio, a Grã-Bretanha declarou guerra contra aquele país, apesar de ela própria haver proibido o consumo da droga em seu território. Derrotada, a China foi obrigada a assinar o Tratado de Nanquim de 1842, por força do qual cedeu Hong Kong, abriu seus portos, aceitou tarifas que não podiam ser alteradas sem o assentimento dos britânicos e a estes pagou indenização pelo ópio perdido e pelos custos da guerra. Nos

\footnotetext{
${ }^{5}$ Dados de 2010.
} 
passos da Grã-Bretanha, outras potências ocidentais vieram a exigir concessões à China. Os Estados Unidos, por exemplo, em 1844 impuseram àquele país um tratado em virtude do qual obtiveram uma série de privilégios comerciais.

A guerra do ópio e o Tratado de Nanquim expuseram a vulnerabilidade da China e abriram o caminho para extensa exploração ocidental. De acordo com o lorde Palmerston, primeiro-ministro britânico de 1859 a 1865, "governos pouco civilizados como os da China, Portugal, América Hispânica precisam de uma bronca [dressing down] a cada oito ou dez anos para se manterem em ordem" (Fulbright, 1966, p. 144). E não foram poucas as "broncas" que os chineses receberam das potências ocidentais nos anos seguintes.

Colonialidade, controle e gerenciamento subjetivo e epistêmico, econômico e político, é, pois, o outro lado pouco evidente mas constitutivo da modernidade, razão pela qual entendemos que a modernidade não pode ser entendida sem a colonialidade e a colonialidade não pode ser superada pela modernidade.

\section{Desocidentalização e decolonialidade}

A despeito de seu grande poder de sedução e alcance global, modernidade e seus correlatos - civilidade, desenvolvimento, democracia e cidadania -, no entanto, começam a apresentar sinais de fraqueza; a mostrar sua natureza discursiva, de verdade construída intersubjetivamente e, portanto, agonística e política; a revelar seu caráter de discurso local, provincial europeu, ainda que universalista e, por isso, mesmo totalitário; e, o que é ainda mais importante, a desvelar seu lado escuro, tenebroso até: um brutal e devastador projeto de dominação cultural, econômica e política do mundo pelo ocidente. Ao mesmo tempo e na mesma proporção, vozes por tanto tempo silenciadas, memórias desde longa data sufocadas, cosmovisões e formas de convivência ao longo dos séculos reprimidas começam a ressurgir, renovadas, transfiguradas, por entre as brechas e fissuras da agora cambaleante modernidade.

Ora, modernidade, até por ser discurso articulado por diferentes povos e etnias europeias em suas interações e intercâmbios entre si e com os demais povos e etnias não europeias ao longo dos tempos, portanto devido a seu caráter dialógico, agonístico, político, nunca foi monolítica, em que pese a ter chegado a ser hegemônica. Ou seja, modernidade é o discurso e o projeto político que têm prevalecido sobre outros discursos e projetos políticos não só externamente, nas interações e intercâmbios dos europeus com não europeus, mas também internamente, nas interações e intercâmbios dos europeus entre si. 
Não apenas isso. Mesmo internamente, nas interações e intercâmbios que os povos e etnias ocidentais, europeus e anglo-americanos, têm mantido entre si, não somente modernidade não é discurso único embora hegemônico, como também é constituída por uma variedade de microdiscursos em relação tensional. Dois desses microdiscursos de modernidade se têm contraposto de uma maneira especial: um tendendo para o coletivismo (marxismo) e outro para o individualismo (liberalismo), com a prevalência atual de uma forma modificada do último (neoliberalismo). (Neo)liberalismo e (neo)marxismo, contudo, partilham do mesmo caráter teleológico, universalista, totalitário, e o mesmo projeto de uniformização do mundo.

Ainda no interior da modernidade, outros microdiscursos se têm intercruzado, em diferentes dimensões e graus, com o (neo)liberalismo e o (neo)marxismo. Nenhum, entretanto, tem provocado tanta tensão e até mesmo rupturas na esfera subjetiva e epistêmica como o articulado a partir da psicanálise e da teoria crítica: o pós-estruturalismo/pós-modernismo. ${ }^{6}$ Os pós-estruturalistas/pós-modernistas foram os primeiros a descortinar o caráter discursivo e local da modernidade e seus correlatos - civilidade, desenvolvimento, democracia e cidadania (Derrida, 1982; Lyotard, 1984; Foucault, 1969). Desde então, um número ainda pequeno, mas intelectualmente influente de ocidentais, europeus e anglo-americanos, começou a perceber que suas cosmologias, artes, filosofia e ciência, sistemas econômico, político e jurídico não são "naturais" nem universais, e que, portanto, não podem ser impostos sobre os outros povos e etnias do planeta. Se esse despertar ou desencantamento epistêmico tem sido ainda insuficiente para desencadear um processo de desimperialização do ocidente, ele certamente está por trás dos vários movimentos contestatórios em emergência no interior de suas fronteiras sempre fluidas, muitos dos quais articulados transnacionalmente, que protestam tanto contra políticas internas excludentes das minorias quanto contra políticas externas intervencionistas.

As brechas e fissuras abertas no discurso de modernidade pelo pósestruturalismo/pós-modernismo têm sido igualmente aproveitadas por intelectuais não ocidentais que atuam em universidades europeias e angloamericanas. Autodenominados pós-coloniais, esses estudiosos têm chamado atenção para o fato de que o discurso de modernidade foi articulado não apenas nas interações e intercâmbios dos europeus entre si, mas também nas interações

\footnotetext{
${ }^{6}$ A separação entre o pós-estruturalismo e o pós-modernismo não é clara. Ainda que Jacques Derrida seja usualmente classificado como pós-estruturalista (ele próprio, no entanto, resistia a essa classificação), Michel Foucault, Roland Barthes e Jean-François Lyotard são comumente posicionados em ambos as categorias.
} 
e intercâmbios dos europeus com os não europeus, nada obstante estes serem representados ora como caricatura, ora como estereótipo, mas sempre como uma síntese aglutinadora de tudo o que aqueles não querem ser. A partir daí, os diferentes estudiosos pós-coloniais, cada um à sua maneira, têm-se engajado na desconstrução do discurso de modernidade com a finalidade de, expurgando-o de seu eurocentrismo, nele identificar verdades construídas nas e pelas interações entre europeus e não europeus, portanto globais (Said, 1978; Hall, 1996; Chakrabarty, 2000).

Mas não são apenas intelectuais não ocidentais atuando em universidades europeias e anglo-americanas que se têm aproveitado da crescente debilitação do discurso de modernidade e do projeto de dominação cultural, econômico e político que ele promove. Povos e etnias inteiras - que, nas interações e intercâmbios nas quais o discurso de modernidade foi articulado, não somente tiveram sua participação negada, mas também, por isso mesmo, por terem sido dessubjetivadas, foram reduzidas a meros objetos de estudo, dominação e exploração de toda sorte - têm ressurgido, renovadas, transfiguradas, por entre as brechas e fissuras que se abrem nesse discurso, a partir da exterioridade nele inventada. E são esses povos e etnias - em alguns casos, o que restou delas - que, muito mais pelas feridas deixadas em seus corpos e pelos estigmas que trazem em sua pele de cor, do que mesmo pelas elaborações de suas consciências divididas e que se movem por entre as fronteiras inventadas no discurso de modernidade, têm desnudado o truculento e arrasador projeto de ocidentalização ou dominação cultural, econômica e política do mundo pelo ocidente nesse discurso por muito tempo escondido e que às escondidas dele se tem alimentado.

Nesse esforço de reexistência, que se tem robustecido na exata medida da debilitação do discurso de modernidade e do projeto de dominação do mundo que ele promove, alguns povos e etnias não ocidentais têm procurado, em suas rearticulações discursivas a partir da exterioridade e movendo-se ao longo de fronteiras inventadas pela modernidade, desta se desligar ou desengajar total e radicalmente, assim como de seu lado inseparável, outrora ocultado mas agora trazido à luz: a colonialidade. Nesse esforço de radical desligamento ou desengajamento decolonial, povos originários ou ab-orígenes de diferentes regiões do mundo, no interior de estados-nações localizados no ocidente ou reproduzidos em sua periferia, mas sempre a partir da exterioridade subjetiva e epistêmica fabricada no discurso de modernidade, rearticulam suas antigas cosmologias, artes, ciências e saberes; formas de intercâmbio não comoditificadas e portanto não capitalistas; modos de interações sociais em que nenhum indivíduo ou grupo possa alcançar supremacia sobre os outros, 
portanto não estatais; tudo num sistema harmonicamente integrado com o meio natural (Tinker, 2008; Simpson, 2008; Coulthard, 2014; Ndebele, 2014).

Os africanos da diáspora, diferentemente - talvez, como já argumentamos, por terem sido desarraigados de suas regiões, povos e etnias originárias e nunca haverem sido propriamente enxertados nas regiões para as quais foram exportados e nas quais foram comercializados, por séculos utilizados como escravos e, mesmo depois de abolido o regime escravista, mantidos numa espécie de não espaço, de não lugar, como uma força laboral de reserva -, nenhuma memória têm para invocar senão a da violência física e simbólica a que foram e são até hoje submetidos, de sua dor física e psíquica, de suas humilhações, mas também de suas movimentações contestatórias, as quais, quando não suprimidas no discurso prevalente, nele têm sido criminalizadas. Assumindo a identidade social na qual, a despeito de toda a variedade de suas origens cosmológicas, culturais, linguísticas e étnicas, eles têm sido homogeneizados - "negro" -, os africanos da diáspora se têm engajado num processo de ressubjetivização no interior do discurso de modernidade, numa luta pelo reconhecimento de seus plenos direitos como cidadãos de estadosnações situados no ocidente ou reproduzidos em sua periferia (Wynter, 2003; Trouillot, 2001).

Outros povos e etnias não ocidentais há, entretanto, que, até por já estarem organizados como estados antes mesmo do que os europeus, com essa formação social - estatal - não apenas têm contestado o conteúdo, mas também têm mudado os termos do discurso eurocêntrico de modernidade e formulado projetos próprios de reexistência. Nesse processo, tais povos e etnias têm rearticulado suas milenares cosmologias, artes, filosofias, ciências e tecnologias, formas de organização econômica e política, apropriando-se de elementos do discurso de modernidade depois de expurgá-los de seu eurocentrismo.

Tomemos a China mais uma vez como caso de estudo. Os chineses, na verdade, articularam um discurso de modernidade próprio, uma espécie de modernidade conflitiva, que em nada se assemelha à modernidade periférica e dependente de ex-colônias como o Brasil de até poucos anos atrás. Quando, a partir de 1949, os chineses incluíram em suas rearticulações discursivas elementos do marxismo e, mais tarde, do liberalismo, não o fizeram com o desejo de ocidentalizar-se, como o fizeram os japoneses, por exemplo, ao adotarem o liberalismo. Ao contrário, os chineses se apropriaram de tais elementos do discurso ocidental num claro esforço de se desocidentalizar. Não é por outra razão que começaram pelo microdiscurso de modernidade derrotado no ocidente, o marxismo, e desde então vêm desenvolvendo uma forma de organização econômica e política, com a posterior apropriação de aspectos do 
liberalismo, que não se subsome nem ao (neo)liberalismo nem ao (neo)marxismo (Lee, 2012; Wang, 2010; Zhang, 2012). Além disso, em que pese a se ter estabelecido no mercado internacional como uma das maiores potências econômicas do mundo - a segunda, muito em breve a primeira, ultrapassando os Estados Unidos -, a China tem-se mantido politicamente alinhada com países não ocidentais, como o Brasil, a Rússia e a África do Sul, ${ }^{7}$ com os quais formou o Brics, com isso rompendo com o centralismo e a mediação dos estados-membros da Organização do Tratado do Atlântico Norte - Otan, principalmente dos Estados Unidos, nas relações internacionais.

Obviamente, tais esforços de desocidentalização têm sido seguidos de tentativas de reocidentalização. Com a decadência da ocidentalização evidenciada durante a presidência de George W. Bush e a emergência da desocidentalização, o ocidente se tem lançado num arrojado projeto de revitalização de sua dominação cultural, econômica e política sobre o resto do mundo sob a liderança de Barack Obama. As recentes movimentações na Ucrânia e no Oriente Médio, as tentativas de limitar a influência da China no Pacífico e o restabelecimento das relações com Cuba vinculado ao controle da América Central e à desestabilização do Brasil, da Argentina e da Venezuela são partes importantes da execução desse projeto.

Contudo, pela primeira vez em muitos séculos, as várias regiões não ocidentais do mundo, o "sul global" e um "hemisfério oriental" ressurgente em termos cada vez mais definidos pelos próprios orientais, têm estabelecido entre si relações culturais, econômicas e políticas sem a intermediação e fora do gerenciamento das potências ocidentais e de seu líder atual, os Estados Unidos, o que parece apontar para um mundo crescentemente multipolar e marcado pelo multilateralismo, em que pese aos esforços do ocidente de retomar seu centenário controle sobre todo o mundo.

\section{Considerações finais}

A natureza discursiva, agonística, política da modernidade e seus correlatos - civilidade, desenvolvimento, democracia e direitos humanos -, assim como de toda e qualquer outra pretensa representação da realidade exterior; seu caráter local, provincial, europeu, ainda que universalista,

\footnotetext{
7 A esta altura de nosso argumento já deve ter ficado suficientemente claro que "ocidente" é mais uma categoria política do que geográfica, inventadas pelos próprios "ocidentais" em suas interações com outros povos e etnias, no curso das quais inventaram também o "oriente" e os "orientais", e mais tarde, com o colapso da União Soviética, o "sul global" como sucedâneo do "terceiro mundo". Nesse sentido, a Austrália é considerada ocidental, ao passo que a África do Sul e o Brasil são mantidos fora do clube.
} 
totalitário; e o brutal e arrasador projeto de dominação cultural, econômica e política que ela promove; tudo isso tem vindo à luz, tem sido claramente revelado nas últimas décadas.

Ao mesmo tempo e na mesma proporção, projetos dissidentes como a desocidentalização têm, cada vez mais, disputado o controle da matriz colonial de poder, que é o fundamento da ideia de modernidade e de sua retórica salvacionista e triunfalista. A desocidentalização se tem apropriado dela sem, contudo, seguir o roteiro. Em consequência, a colonialidade do poder se tem tornado mais compartilhada, assim como mais compartilhado se tem tornado o poder de decisão nas relacionais internacionais, desde o Conselho de Segurança da Organização das Nações Unidas até a Organização Mundial do Comércio. Enquanto os Estados Unidos ampliam suas bases comerciais e militares no Pacífico, a China trabalha para estender a rota da seda, por terra e mar, de Pequim a Roterdã. É claro que nem a desocidentalização nem a reocidentalização - os esforços dos Estados Unidos e da Europa de manter a liderança mundial - são necessariamente boas para o planeta. A desocidentalização, entretanto, está criando uma classe média global que não foi possível sob a ocidentalização. Afora isso, a desocidentalização está, em boa medida, impedindo a marcha na direção de um fascismo hegemônico e global.

Daí a importância do pensamento decolonial como instrumento de análise das drásticas mudanças por que passa a ordem mundial, cujos sinais se espalham por toda a parte, da Ucrânia ao Oriente Médio, de Iguala no México a Ferguson nos Estados Unidos, do escândalo da Petrobras ao caso Nisman na Argentina. Vulcões estão entrando em erupção por todos os lugares, e uma explicação para isso pode ser a gradativa perda de privilégios do ocidente e o crescente despertamento do mundo para além da Europa e dos Estados Unidos - cerca de $80 \%$ da população do planeta -, despertamento que aqui significa despertamento do pesadelo da modernidade. As respostas, obviamente, têm variado, mas antes de fazer o papel de juiz e decretar o que é melhor e pior para o mundo, é fundamental entender que estamos a testemunhar as consequências da dupla face da modernidade: de um lado, a retórica da salvação e bemaventurança por meio do progresso e do desenvolvimento e, de outro, a lógica da colonialidade, ou seja, a violência, a exploração e a expropriação necessárias à realização da promessa de salvação e bem-aventurança. Se para nada mais serve, o pensamento decolonial ao menos contribui ao entendimento de que a nova ordem mundial não é aquela ambicionada por George Bush, o pai, com a guerra do golfo, mas sim os procedimentos "legais" de desocidentalização e os "ilegais" dos cartéis - em busca de lucros econômicos, que é o que aprenderam com o capitalismo - e do Estado Islâmico - em busca da constituição de 
um estado próprio, que é o que o euro-moderno e democrático estado-nação lhe ensinou.

É claro que esforços como os da China e de outras potências (re)emergentes em diferentes regiões não ocidentais do mundo de rearticular os próprios discursos e projetos de reexistência apropriando-se de elementos da modernidade, ainda que depois de expurgá-los de seu eurocentrismo, podem eventualmente ter o efeito contrário e indesejado de reproduzir aspectos de sua face indissociável: a colonialidade. Ademais, apesar de, ao longo de todo seu passado como uma das maiores e mais poderosas civilizações do mundo, os chineses nunca terem exibido a mesma sanha imperialista dos ocidentais, nada garante que eles não venham a fazê-lo nos próximos anos quando chegarem a desbancar os anglo-americanos como a maior potência econômica de todos os tempos, tanto mais agora que reproduziram, ainda que de maneira modificada, adaptada a seus princípios e práticas milenares, a combinação ocidental mercado-estado-nação - forma de organização econômica e política que se tem revelado expansionista e destruidora da cultura dos povos e etnias e do meio natural sobre os quais ela avança. Experiências como a da China, portanto, só corroboram nosso entendimento da inviabilidade de uma decolonialidade radical por meio do estado e da insuperabilidade da colonialidade por intermédio da modernidade ou modernização. No entanto, visto por outro ângulo, pensar que os chineses seguirão os passos do imperialismo ocidental é, em si, uma maneira bem ocidental e eurocêntrica de raciocinar: "Eles farão o que nós fizemos!". Além do mais, é uma clara manifestação de medo: medo de que a China cause ao ocidente os mesmos danos que o imperialismo ocidental impingiu à China e ao resto do mundo.

Evidentemente, a desocidentalização e a decolonialidade, tanto quanto a reocidentalização e tudo o mais, têm limites. Mas, reiteramos, pensar em limites é, de certa forma, colocar-se na posição de uma mente soberana que julga sem ser julgada, de alguém que consegue ver os limites dos outros sem enxergar os próprios. Se formos entrar na análise dos limites, o primeiro limite a analisar teria de ser os limites de quem analisa os limites. Do contrário, continuaríamos a nos colocar no marco zero do conhecimento, na epistemologia imperialista da modernidade. Não há lugar em que possamos analisar limites sem que nos vejamos analisando tais limites, inclusive os nossos próprios. Estamos todos dentro do mundo. Não há qualquer exterioridade sociológica em que um observador possa posicionar-se e a partir da qual possa analisar o que quer que seja. Esse também é, em parte, o fim do sonho das modernas ciências sociais.

Em todo caso, quaisquer que sejam os limites da desocidentalização e as dificuldades da decolonialidade, em vez de levar à desistência, devem 
conduzir-nos a uma maior radicalização do empreendimento. Até porque as alternativas que se nos apresentam não são nada encorajadoras. Ou radicalizamos nossos esforços no sentido de nos desligar ou desengajar da modernidade-colonialidade, abrindo assim as possibilidades para a imaginação de novas formas de interações e intercâmbios humanos, num sistema mais harmonicamente integrado com o meio natural, ou, sucumbindo a uma suposta inexorabilidade dos acontecimentos, restringimo-nos tão somente a continuar discutindo no Brasil se já somos ou não suficientemente modernos, enquanto todos nós - brasileiros e demais habitantes do planeta; situados no centro, na periferia ou na periferia da periferia; colonizadores, colonizados-colonizadores ou simplesmente colonizados - caminhamos a passos cada vez mais largos para o último e derradeiro holocausto produzido pela modernidade, agora não mais apenas de ameríndios, negros, judeus ou qualquer Outro dessubjetivizado - portanto descartável quando não mais utilizável -, mas de todos nós. Em outras palavras, ou sonhamos ou morremos!

\section{Referências}

COULTHARD, Glen S. Read skin, white mask: rejecting the colonial politics of recognition. Minneapolis: University of Minnesota Press, 2014.

CHAKRABARTY, Dipesh. Provincializing Europe. Princeton: University of Princeton, 2000.

DEPEN, Departamento Penitenciário Nacional. Relatório Estatístico/Analítico do Sistema Prisional Brasileiro. dez. $2012<$ http://justica.gov.br/seus-direitos/ politica-penal/transparencia-institucional/estatisticas-prisional/relatorios-estatisticosanaliticos-do-sistema-prisional> (6 maio 2015).

DERRIDA, Jacques. Différance. In: Jacques Derrida. Margins of philosophy. Chicago: University of Chicago Press, 1982.

DUSSEL, Enrique. Eurocentrism and modernity: introduction to the Frankfurt Lectures. Boundary 2, v. 20, n. 3, p. 65-76, 1993.

DUSSEL, Enrique. Europa, modernidade e eurocentrismo. In: Edgardo Lander (org.). Colonialidade do saber: eurocentrismo e ciências sociais. Buenos Aires: Clacso, 2005. p. 24-32.

FBI - Federal Bureau of Investigation. Crime in the United States. $2011<\mathrm{http} / /$ www.fbi.gov/about-us/cjis/ucr/crime-in-the-u.s/2011/crime-in-the-u.s.-2011/offensesknown-to-law-enforcement/expanded/expanded-homicide-data> (6 maio 2015).

FEDERAL Bureau of Prisons. Inmate Race. Última atualização: 28 mar. $2015<$ http:// www.bop.gov/about/statistics/statistics_inmate_race.jsp> (6 maio 2015).

FOUCAULT, Michel. L'archéologie du savoir. Paris: Gallimard, 1969.

FULBRIGHT, J. William. The arrogance of power. Nova York: Random House, 1966. 
HALL, Stuart. The West and the rest: discourse and power. In: Stuart Hall et al. (orgs.). Modernity: introduction to the modern society. Oxford: Blackwell, 1996.

IBGE, Instituto Brasileiro de Geografia e Estatística. Censo $2010<\mathrm{http}: / /$ censo2010. ibge.gov.br/resultados> (6 maio 2015).

LEE Kuan Yew. The grand master's insight on China, the United States and the world. Cambridge: The MIT Press, 2012.

LYOTARD, Jean-François. The postmodern condition: a report on knowledge. Minneapolis: Univ. Minn. Press, 1984.

MIGNOLO, Walter D. A colonialidade de cabo a rabo: o hemisfério ocidental no horizonte conceitual da modernidade. In: Edgardo Lander (org.). Colonialidade do saber: eurocentrismo e ciências sociais. Buenos Aires: Clacso, 2005. p. 33-49.

MIGNOLO, Walter D. Theorizing from the borders: shifting to geo- and body-politics of knowledge. European Journal of Social Theory, v. 9, n. 2, p. 205-22, 2006.

MIGNOLO, Walter D. The darker side of Western modernity. Durham: Duke University Press, 2011a.

MIGNOLO, Walter D. Cosmopolitan localism: a decolonial shifting of the Kantian's legacies. Localities, v. 1, p. 11-45, 2011b.

MIGNOLO, Walter D. Geopolítica de la sensibilidad y del conocimiento: sobre (de) colonialidad, pensamiento fronterizo y desobediencia epistémica. Revista de Filosofía, v. 74, p. 7-23, 2013.

MIGNOLO, Walter D. Democracia liberal, camino de la autoridad humana y transición al vivir bien. In: Debora Messenberg G.; Flávia L. Barros; Julio R. S. Pinto (orgs.). Desafios da consolidação democrática na América Latina. Sociedade e Estado, v. 29, n. 1, 2014, p. 21-44.

NDEBELE, Njabulo S. To be or not to be, no longer at ease. Palestra de Abertura da 40a Conferência de Associação Africana de Literatura na Universidade de Witwatersrand, Joanesburgo, 10 abr. 2014.

QUIJANO, Aníbal. Colonialidade del poder, cultura y conocimiento en América Latina. Anuario Mariateguiano, v. 9, n. 9, p. 113-22, 1998.

QUIJANO, Aníbal. Colonialidade do poder, eurocentrismo e América Latina. In: Edgardo Lander (org.). Colonialidade do saber: eurocentrismo e ciências sociais. Buenos Aires: Clacso, 2005. p. 107-30.

QUIJANO, Aníbal. Coloniality and modernity/rationality. Cultural Studies, v. 21, n. 2-3, p. 168-178, 2007.

SAID, Edward. Orientalism. Nova York: Vintage, 1978.

SIMPSON, Leanne. Oshkimaadiziig, The new people e Our elder brothers. In: Lighting the eighth fire: the liberation, resurgence, and protection of Indigenous Nations. Winnipeg: Arbeiter Ring Pub., 2008. p. 13-21, 73-87. 
SMITH, Linda Tuhiwai. Decolonizing methodologies: research and indigenous peoples. Dunedin: University of Otago Press, 2006.

TINKER, George. Struggle, resistance, liberation, and theological methodology indigenous: peoples and the two-thirds world. In: American Indian liberation: a theology of sovereignty. Maryknoll, NY: Orbis Book, 2008. p. 17-35.

TROUILLOT, Michel-Rolph. North Atlantic universal: analytical fictions, 1492-1945. The South Atlantic Quarterly, v. 101, n. 4, p. 839-858, 2002.

US Census Bureau. USA Quick Facts. Última revisão: 31 mar. $2015<$ http://quickfacts. census.gov/qfd/states/00000.html> (6 maio 2015).

WAISEFISZ, Julio J. Mapa da violência 2012: a cor dos homicídios no Brasil. Rio de Janeiro: Cebela, Flacso, Brasília: Seppir/PR, $2012<$ http://www.mapadaviolencia.org. br/mapa2012_cor.php> (6 maio 2015).

WANG Hui. An interview concerning modernity. In: The end of the revolution: China and the limits of modernity. Londres: Verso, 2010. p. 69-104.

WYNTER, Sylvia. Unsettling the coloniality of being/power/truth/freedom: towards the human, after man, its overrepresentation - an argument. The New Centennial Review, v. 3, n. 3, p. 257-337, 2003.

ZHANG Weiwei. The China wave: rise of a civilizational state. Hackensack, NJ: World Century, 2012.

Recebido em: 8 maio 2015

Aprovado em: 30 set. 2015

Autor correspondente:

Júlio Roberto de Souza Pinto

Câmara dos Deputados, Centro de Formação, Treinamento e Aperfeiçoamento

Via N3 - Projeção L, Complexo Avançado da Câmara dos Deputados, Bloco B

Setor de Garagens Ministeriais Norte

70160-900 Brasília, DF, Brasil 